\title{
A CASE STUDY AT STARNBERGER SEE FOR HYPERSPECTRAL BATHYMETRY MAPPING USING INVERSE MODELING
}

\author{
Peter Gege \\ Deutsches Zentrum für Luft- und Raumfahrt (DLR), Institut für Methodik der Fernerkundung, \\ Oberpfaffenhofen, 82234 Wessling, Germany
}

\begin{abstract}
In coastal regions, hyperspectral remote sensing is becoming an established method to map water depth. For inland waters however, only few studies based on empirical methods have been published so far. This paper presents a study for the German lake Starnberger See using a physically based approach. Hyperspectral data were acquired from airplane using a HySpex VNIR-1600 sensor. They were processed by inverse modeling using a radiative-transfer based analytical model. In situ measurements were taken to decide which model parameters to fit and which to keep constant during data analysis, and they were used to initialize the parameters. Bottom reflectance was determined from the image itself. An echo sounding survey was undertaken for validation. For the studied area, bathymetry could be mapped up to a depth of $8 \mathrm{~m}$ with a rms error of $37 \mathrm{~cm}$. Accuracies of 10-25 cm from 0-4 $\mathrm{m}$ and 35-65 cm from 4-8 $\mathrm{m}$ seem possible if the remaining systematic errors can be further reduced, e.g. by accounting for changes of bottom reflectance.
\end{abstract}

Index Terms - hyperspectral, inversion, bathymetry, airborne sensor

\section{INTRODUCTION}

Optical remote sensing allows to determine water depth [1] because water attenuates the signal from the bottom with a strong wavelength dependency. The signal depends however not only on water depth and the attenuation coefficient of pure water, but also on concentration and optical properties of several water constituents, bottom reflectance, reflections at the water surface, and on viewing and illumination geometry. To separate all these effects reliably, the measurements must be well-calibrated and resolve sufficient spectral details, and data analysis must be based on a radiative-transfer model capable of simulating the measurements considering all relevant effects. Such a model is applied here to an image acquired by the hyperspectral sensor HySpex VNIR-1600 [2] at the German lake Starnberger See (Figure 1).

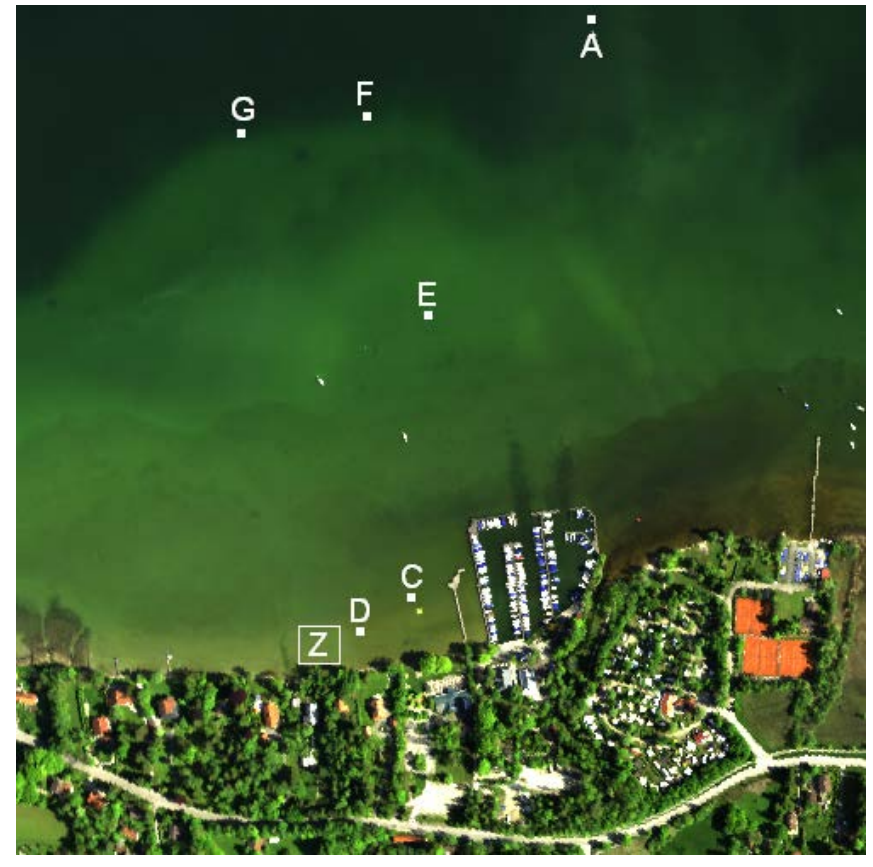

Figure 1: Image of the test site $(1 \mathrm{~km} \times 1 \mathrm{~km})$. In situ measurements were made at stations A to $G$ (station B is outside the image), bottom reflectance was determined for area $\mathrm{Z}$.

\section{MODEL}

A water layer of certain thickness alters bottom reflectance with a characteristic wavelength dependency. The resulting remote sensing reflectance $R_{r s}$ is modeled here using the analytic equation of Albert [3][4]:

$$
\begin{aligned}
& R_{r s}^{s h-}(\lambda)=R_{r s}^{\text {deep- }}(\lambda) \cdot\left[1-A_{r s, 1} \cdot \exp \left\{-\left(K_{d}(\lambda)+k_{u W}(\lambda)\right) \cdot z_{B}\right\}\right] \\
& +A_{r s, 2} \cdot R_{r s}^{b}(\lambda) \cdot \exp \left\{-\left(K_{d}(\lambda)+k_{u B}(\lambda)\right) \cdot z_{B}\right\}
\end{aligned}
$$

The superscript sh indicates shallow water, deep deep water, $b$ bottom, the '-' symbol a measurement just below the water surface, and the symbol $\lambda$ denotes wavelength. The first term on the right-hand side is the contribution of a water layer of thickness $z_{B}$, the second term of the bottom. The 
reflected light has passed the water column twice. The corresponding extinction is described by the attenuation coefficients $K_{d}$ for downwelling irradiance, $k_{u W}$ for upwelling radiance originating from the water layer, and $k_{u B}$ for upwelling radiance from the bottom. These three coefficients are calculated as a function of the sun zenith angle, viewing direction and the concentrations of water constituents using equations also derived by Albert [3][4]. $A_{r s, 1}$ and $A_{r s, 2}$ are empirical constants.

The remote sensing reflectance measured by an above-water sensor is related to $R_{r s}{ }^{s h-}$ as follows:

$$
R_{r s}^{s h}(\lambda)=\frac{\zeta \cdot R_{r s}^{s h-}(\lambda)}{1-\Gamma \cdot R_{r s}^{s h-}(\lambda)}+R_{r s}^{s u r f}(\lambda) .
$$

$\zeta \approx 0.52$ is the water-to-air radiance-divergence factor [5], the denominator with $\Gamma \approx 1.6$ accounts for the effects of internal reflection from water to air [5], and $R_{r s}{ }^{\text {surf }}$ are the reflections at the water surface.

All calculations of this study are made with an implementation of Eqs. (1) and (2) in the software WASI [6][7]. The Water Colour Simulator WASI is a tool for simulating and analysing different types of spectral measurements above the water surface and in water. It has been extended recently by the module WASI-2D for processing atmospherically corrected multi- and hyperspectral image data [8]. In this extension, the irradiance model of Gregg and Carder [9] was adopted to calculate $R_{r s}^{\text {surf }}$. The GC model separates the downwelling irradiance $E_{d}$ into three components, namely the direct solar irradiance $E_{d d}$ and the diffuse components caused by molecule scattering, $E_{d s r}$, and by aerosol scattering, $E_{d s a}$, and it provides an analytic equation for each component. WASI2D models the reflected radiance of the sky as a weighted sum of these three components:

$L_{s}(\lambda)=g_{d d} \cdot E_{d d}(\lambda)+g_{d s r} \cdot E_{d s r}(\lambda)+g_{d s a} \cdot E_{d s a}(\lambda)$

with $g_{d d}, g_{d s r}$ and $g_{d s a}$ representing the relative intensity of each 'light source'. For the hypothetical case of a uniform sky, a plane water surface and a viewing direction avoiding specular reflection of the sun disk, it is $g_{d d}=0$ and $g_{d s r}=g_{d s a}$ $=1 / \pi=0.32$. As the $g$ 's are not well known under real conditions, they can be treated as fit parameters during data analysis. $R_{r s}^{\text {surf }}$ is calulated as

$$
R_{r s}^{\text {surf }}(\lambda)=\rho_{L s} \cdot \frac{L_{s}(\lambda)}{E_{d}(\lambda)}
$$

with $\rho_{L s}$ the Fresnel reflectance for unpolarized light; $\rho_{L s}=$ 0.02 for viewing angles near nadir. For more details see [8].

\section{DATA}

Test site was a shallow water area near the marina of Seeshaupt at the southern end of the lake Starnberger See (Figure 1). The lake, which is located in southern Germany, is mesotrophic with a tendency to oligotrophic. With its area of $65 \mathrm{~km}^{2}$ it is Germany's fifth largest lake. The average depth is $53 \mathrm{~m}$, the maximum depth $128 \mathrm{~m}$.

An airborne campaign was conducted at the test site on May 14, 2012, using a HySpex VNIR-1600 camera [2]. The HySpex sensor covers the spectral range from 416 to 992 $\mathrm{nm}$ at a sampling interval of $3.6 \mathrm{~nm}$. The used foreoptics $(2 \mathrm{x}$ field-of-view expander) provides a field of view of $33.2^{\circ}$, corresponding to a swath width of $1.5 \mathrm{~km}$ at the chosen flight altitude above ground of $2450 \mathrm{~m}$. The integration time was $22 \mathrm{~ms}$.

Accompanying in situ measurements were made from two boats. One boat collected water samples, measured optical properties and determined Secchi depth at stations A to $G$. The other boat was equipped with an echo sounder (BioSonics MX Aquatic Habitat Echosounder; accuracy: 1.7 $\mathrm{cm} \pm 0.2 \%$ of depth) and measured transects of water depth.

The raw HySpex data were converted into units of spectral radiance using software developed at DLR and sensor parameters determined at DLR's calibration home base [10]. The calibrated image was atmospherically corrected and converted into units of irradiance reflectance $R(\lambda)$ using ATCOR-4 [11], and then geometrically corrected and geo-referenced using ORTHO [12]. The geometrically resampled image has a pixel size of $2 \times 2 \mathrm{~m}^{2}$.

\section{REGIONAL OPTIMIZATION}

Accounting for regional information usually improves data analysis compared to generic algorithms which are developed to cover wide parameters ranges. A first step for regional optimization is to estimate the actual parameter ranges using in situ measurements. The results of the boat campaign at the test site are summarized in Table 1.

Table 1: Results of in situ measurements.

\begin{tabular}{ccccccc}
\hline Station & $\begin{array}{c}C \\
{[\mu \mathrm{g} / \mathrm{l}]}\end{array}$ & $\begin{array}{c}X \\
{[\mathrm{mg} / \mathrm{l}]}\end{array}$ & $\begin{array}{c}Y \\
{\left[\mathrm{~m}^{-1}\right]}\end{array}$ & $\begin{array}{c}S \\
{\left[\mathrm{~nm}^{-1}\right]}\end{array}$ & $\begin{array}{c}\text { Secchi } \\
{[\mathrm{m}]}\end{array}$ & $\begin{array}{c}Z_{B} \\
{[\mathrm{~m}]}\end{array}$ \\
\hline A & 1.77 & 1.21 & 0.56 & 0.0128 & 4.20 & 13 \\
B & 1.81 & 0.91 & 0.46 & 0.0150 & 4.70 & $>11$ \\
$\mathrm{C}$ & 1.67 & 2.89 & 0.76 & 0.0149 & $>z_{B}$ & 0.9 \\
D & 1.71 & 2.93 & 1.05 & 0.0133 & $>z_{B}$ & 0.8 \\
E & 1.86 & 1.59 & 0.50 & 0.0126 & $>z_{B}$ & 2.8 \\
F & 1.34 & 1.28 & 0.49 & 0.0145 & 3.50 & 4.4 \\
G & 1.54 & 0.76 & 0.54 & 0.0130 & 4.50 & 5.6 \\
\hline mean & 1.67 & 1.65 & 0.62 & 0.0137 & 4.23 & \\
stddev & 0.18 & 0.90 & 0.21 & 0.0010 & 0.53 & \\
\hline
\end{tabular}




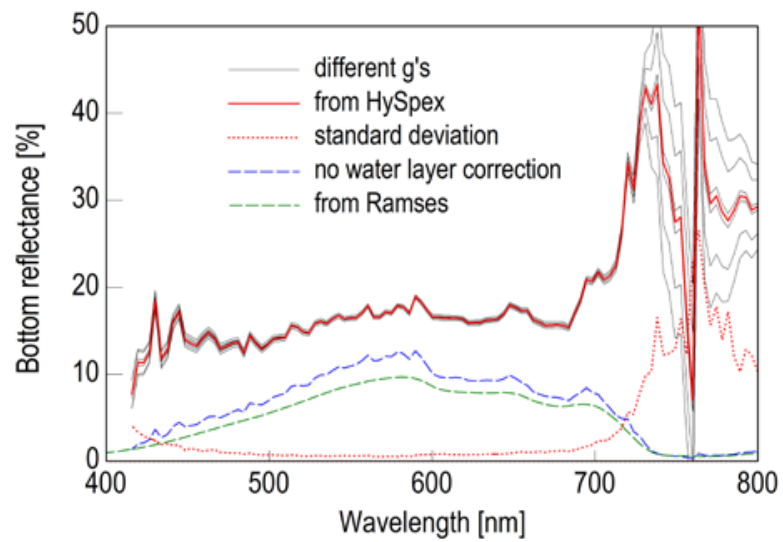

Figure 3: Bottom reflectance.

Chlorophyll-a concentration $C$ was similar at all stations, while suspended particle concentration $X$ varied by a factor of 4. Gelbstoff concentration $Y$, defined as absorption at 440 $\mathrm{nm}$, was fairly constant at $0.51 \pm 0.04 \mathrm{~m}^{-1}$ for the deeper water stations A, B, E, F, G, but almost double at the stations $\mathrm{C}$ and $\mathrm{D}$ close to the shoreline. The spectral slope $S$ of Gelbstoff absorption varies slightly around the typical value of $0.014 \mathrm{~nm}^{-1}$ observed in many water types around the world. Gelbstoff dominates absorption in the blue-green spectral range: the specific absorption coefficient of phytoplankton is typically $0.03-0.05 \mathrm{~m}^{2} / \mathrm{mg}$ at $440 \mathrm{~nm}$, thus the measured $C$ 's correspond to absorption coefficients of $0.05-0.08 \mathrm{~m}^{-1}$, which is approximately 10 times less than absorption by Gelbstoff. $C, X, Y$ and $S$ are used to calculate in Eq. (1) the apparent optical properties (AOPs) $R_{r s}{ }^{\text {deep- }}, K_{d}$, $k_{u W}$ and $k_{u B}$ of the water layer. As a consequence of the in situ measurements, $C, X, Y$ and $S$ can be initialized properly, and it can be decided which of them to treat as constant $(C)$ and which as fit parameters $(X, Y, S)$.

Besides the optical properties of the water layer, bottom reflectance has a strong impact on the accuracy of water depth determination. $R_{r s}{ }^{b}$ was determined directly from the HySpex image as follows. First the AOPs of water near the shoreline were calculated using equations given in [8] and the average in situ parameters at stations C and D: $C$ $=1.7 \mu \mathrm{g} / \mathrm{l}, X=2.9 \mathrm{mg} / \mathrm{l}, Y=0.9 \mathrm{~m}^{-1}$ and $S=0.014 \mathrm{~nm}^{-1}$. Then a very shallow homogeneous area was selected in the image (area Z of Figure 1; $0.64 \mathrm{~m}$ mean depth) for which echo sounding measurements are available. For the 62 pixels of this area with known $z_{B}$, bottom reflectance was calculated by solving Eq. (1) for $R_{r s}{ }^{b}(\lambda)$. Mean and standard deviation of $\pi \times R_{r s}^{b}(\lambda)$ are shown in Figure 2 (red). They were obtained using $g_{d d}=0.01$ (sun glint), $g_{d s r}=g_{d s a}=0.32$ (sky glint) and $\rho_{L s}=0.02$ to model the surface reflections. For comparison also two bottom reflectance spectra are shown in Figure 2 which were not corrected for extinction of the water layer. The one (blue dashed line) was calculated

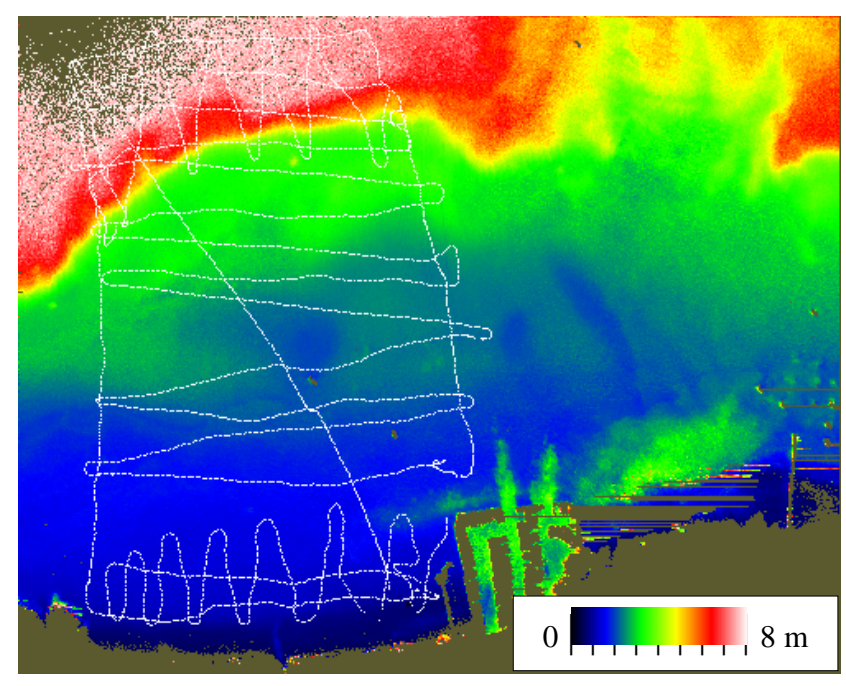

Figure 2: Water depth derived from HySpex, superimposed with the track of the echo sounding survey. Non-water areas and depths $>8 \mathrm{~m}$ are masked (olive green).

as before, but $z_{B}=0$ was set. The other (green dashed line) is from an underwater measurement of a TriOS RAMSES sensor system at station D. Both spectra differ strongly from the HySpex-derived curve, demonstrating the importance to correct the water layer.

In order to study the influence of not well known parameters on the derived bottom reflectance, the calculations were repeated for $g_{d d}=0$ and 0.02 , and for $g_{d s r}$ and $g_{d s a}$ equal to 0.26 and 0.38 (Figure 2, black curves). The impact is small below $725 \mathrm{~nm}$, but $R_{r s}{ }^{b}(\lambda)$ is very sensitive to the $g$ 's above $725 \mathrm{~nm}$. In consequence, the HySpex bands above $725 \mathrm{~nm}$ are not further used.

\section{RESULTS AND DISCUSSION}

Each pixel of the atmospherically corrected HySpex image was converted from irradiance reflectance to remote sensing reflectance using $R_{r s}{ }^{s h}(\lambda)=R(\lambda) / \pi$ and then inverted using Eq. (2). Since Gelbstoff dominates absorption at the test site, while phytoplankton absorption plays a minor role and $C$ was not much variable, the Gelbstoff parameters $Y$ and $S$ were treated as fit parameters and $C$ as constant. The phytoplankton type was set to dinoflagellates using the specific absorption coefficient from the WASI data base. Suspended matter concentration $X$ was fit parameter, its backscattering was treated as wavelength-independent with a backscattering coefficient of $0.0086 \mathrm{~m}^{2} / \mathrm{g}$, which is the default of WASI. $C, X, Y$ and $S$ were initialized using the mean values of Table 1 . The HySpex-derived spectrum $R_{r s}{ }^{b}(\lambda)$ from Figure 2 was used to describe bottom reflectance of all pixels. The reflections at the water surface were calculated using Eq. (4) with $g_{d d}=0.01$ (estimated from deep water areas), $g_{d s r}=g_{d s a}=0.32$ and $\rho_{L s}=0.02$. 


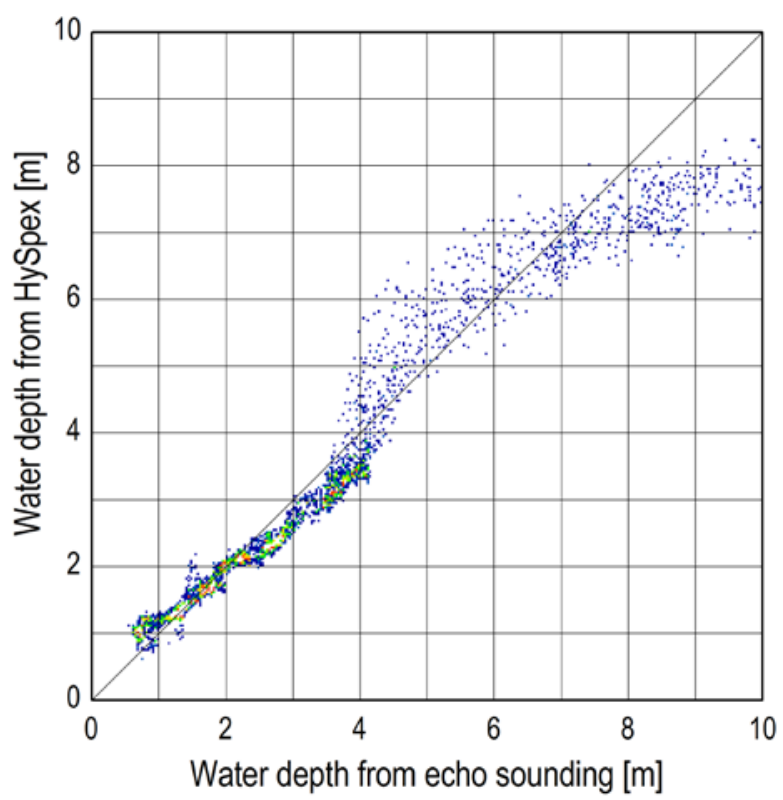

Figure 4: Validation comparison between 4148 match-ups of HySpex-derived and echo sounding depths.

The resulting map of water depth is shown in Figure 3. The map is noise-free and shows clear bathymetry structures. Some artefacts can be observed in the bottom right part of the image: striping occurs occasionally to the right of masked pixels. The 4148 water depth measurements of the echo sounding survey (white pixels in Figure 3) are used for validation. Figure 4 shows the comparison with the HySpex derived $z_{B}$ values. The correlation is very high up to $4 \mathrm{~m}$, then noise increases, and above $8 \mathrm{~m}$ the depths derived from HySpex scatter between 7 and $8 \mathrm{~m}$. The upper limit of depth determination is thus around $8 \mathrm{~m}$. For the useful range of 0-8 $\mathrm{m}$, HySpex underestimates water depth on average by $10 \mathrm{~cm}$ (bias) at a standard deviation (stddev) of $35 \mathrm{~cm}$. The root mean square error, RMSE $=\left(\text { bias }^{2}+\text { stddev }^{2}\right)^{1 / 2}$, is 37 $\mathrm{cm}$. A depth dependent statistics is given in Table 2 .

While the RMSE is a measure of the actual accuracy, the stddev indicates the potential accuracy of method and data if the systematic errors (quantified by the bias) could be eliminated. According to Table 2, accuracies of 10-25 cm from 0-4 m depth and 35-65 cm from 4-8 $\mathrm{m}$ seem possible. Systematic errors are probably introduced by using a single bottom reflectance spectrum, because it is known from diving that the bottom at the test site changes from soft

Table 2: Correspondence between HySpex-derived and echo sounding depths.

\begin{tabular}{lccccccccc}
\hline Range [m] & $\mathbf{0 - 8}$ & $0-1$ & $1-2$ & $2-3$ & $3-4$ & $4-5$ & $5-6$ & $6-7$ & $7-8$ \\
$\mathrm{~N}$ & $\mathbf{3 9 4 7}$ & 355 & 1217 & 906 & 801 & 297 & 116 & 126 & 129 \\
bias $[\mathrm{cm}]$ & $\mathbf{- 1 0}$ & 28 & 0.51 & -26 & -38 & 8.4 & 47 & 0.27 & -41 \\
stddev $[\mathrm{cm}]$ & $\mathbf{3 5}$ & 15 & 11 & 15 & 25 & 65 & 46 & 43 & 34 \\
RMSE $[\mathrm{cm}]$ & $\mathbf{3 7}$ & 32 & 11 & 30 & 46 & 65 & 65 & 43 & 54 \\
\hline
\end{tabular}

sediment cover to stony ground. Further improvements require a set of representative water-column corrected bottom reflectance spectra.

\section{ACKNOWLEDGMENT}

DLR's flight department and OpAiRS team are acknowledged for the flight campaign, and the Limnological Station of TU Munich for the in situ measurements. Special thanks to N. Pinnel for campaign organisation and field data acquisition, K. Linnemann for laboratory analyses, S. Rößler and P. Wolf for the echo sounding data, and D. Rogge for processing the HySpex image. Two anonymous reviewers provided helpful comments.

\section{REFERENCES}

[1] A.G. Dekker et al., "Intercomparison of shallow water bathymetry, hydro-optics, and benthos mapping techniques in Australian and Caribbean coastal environments," Limnology and Oceanography: Methods, vol. 9, pp. 396-425, 2011.

[2] NEO (2014). HySpex hyperspectral cameras. http://www.hyspex.no/

[3] A. Albert, C.D. Mobley, "An analytical model for subsurface irradiance and remote sensing reflectance in deep and shallow case-2 waters," Optics Express, vol. 11, pp. 2873-2890, 2003.

[4] A. Albert (2004). Inversion technique for optical remote sensing in shallow water. Ph.D. Dissertation, Universität Hamburg, Germany, 188pp.

[5] Z.P. Lee et al, "Hyperspectral remote sensing for shallow waters: 1. A semianalytical model," Applied Optics, vol. 37, pp. 6329-6338, 1998.

[6] P. Gege, "The water color simulator WASI: an integrating software tool for analysis and simulation of optical in situ spectra,“ Computers \& Geosciences, vol. 30, pp. 523-532, 2004.

[7] P. Gege, A. Albert (2006). A tool for inverse modeling of spectral measurements in deep and shallow waters, In: Richardson, L.L., LeDrew, E.F. (Eds.) Remote Sensing of Aquatic Coastal Ecosystem Processes: Science and Management Applications, Springer, pp. 81-109.

[8] P. Gege, "WASI-2D: A software tool for regionally optimized analysis of imaging spectrometer data from deep and shallow waters,” Computers \& Geosciences, vol. 62, pp. 208-215, 2014.

[9] W.W. Gregg, K.L. Carder, "A simple spectral solar irradiance model for cloudless maritime atmospheres," Limnology and Oceanography, vol. 35, pp. 1657-1675, 1990.

[10] K. Lenhard, A. Baumgartner, T. Schwarzmaier (2014): Independent laboratory characterization of NEO HySpex imaging spectrometers VNIR-1600 and SWIR-320M-E. In preparation.

[11] R. Richter, D. Schläpfer, A. Müller (2006). An automatic atmospheric correction algorithm for visible/NIR imagery. International Journal of Remote Sensing, 27, 2077-2085.

[12] R. Müller, S. Holzwarth, M. Habermeyer, A. Müller (2005). Ortho image production within an automatic processing chain for hyperspectral airborne scanner ARES. Proceedings EARSeL Workshop 3D-Remote Sensing, Porto, Portugal, June 10-11, 2005. 